\title{
ABOUT THE CONCEPT FOR THE DEVELOPMENT OF MOTOR TRANSPORT IN GEORGIA BASED ON INTELLIGENT TRANSPORT SYSTEMS
}

\author{
Vakhtang Bogvelishvili \\ Ph. Doctor, Associate Professor, \\ Georgian Technical University, Tbilisi, Georgia \\ DOI: https://doi.org/10.31435/rsglobal_conf/30112020/7265
}

\begin{abstract}
The growth of motorization is followed by a number of problems, including low speed of communication, congestion of the road network, high accident rate, deterioration of the environmental situation. Improving the quality and safety of road traffic can be achieved through the creation of an intelligent transport system, which, being a global trend, can dramatically improve the quality and safety of road traffic. The long-term concept for the development of Georgia's transport should be based on the advanced achievements of science and technology. The state strategy for the development of an intelligent transport system should reflect the vision of this industry in the long term. The national intelligent transport system must be unified with international intelligent transport systems, therefore it is advisable to create such a system in cooperation with European countries, taking into account local specific features.
\end{abstract}

Keywords: transportation system, intelligent transportation system, innovations, management, development concept.

Введение. За последние 10 лет число автомобилей в Грузии, с населением 3,7 млн человек, увеличилось в 2 раза, превысило 1,5 млн единиц и продолжает расти. Рост автомобилизации вызвал ряд проблем, связанных с увеличением нагрузки на улично-дорожную сеть, особенно в городах: снизилась скорость сообщения, ухудшились режимы движения, появились перегрузки улично-дорожной сети, увеличились выбросы вредных веществ в атмосферу и уровень транспортного шума, возросло количество аварий.

Дорожное движение содержит аварийную, экологическую, экономическую и социальную угрозы. Для участников движения из всех угроз наиважнейшей является аварийность, поскольку непосредственно касается жизни, здоровья и благополучия граждан, поэтому борьба с аварийностью имеет большую социальную значимость, и ее необходимо рассматривать на государственном уровне. Ежегодно в мире погибает более 1,3 млн человек и около 50 млн получают травмы. В Грузии каждый год происходит более 6 тыс. дорожнотранспортных происшествии, в которых погибают около 500 и получают ранения более 9 тыс. человек. Почти 21 тыс. км автомобильных дорог на территории 69,7 тыс. км ${ }^{2}$ имеют стратегическое значение для страны. Они связывают и обеспечивают жизнедеятельность всех городов и населенных пунктов на всей территории государства, во многом определяют возможности развития регионов, реализацию транзитного потенциала страны.

Переходя к интенсивному инновационному развитию, Грузия стремится включится в глобальную экономику, что требует принятия адекватных стратегических решений по усовершенствованию транспортного-дорожного комплекса. Долгосрочная концепция формирования транспорта, должна быть инновационной, т.е. опираться на передовые достижения науки и техники.

Основная часть. Концепция развития транспортной системы Грузии должна ориентироваться как на интенсивное. так и на экстенсивное развитие транспортной системы. Под интенсивным развитием подразумевается более эффективное использование существующих ресурсов, а под экстенсивным развитием - строительство новых дорог, транспортных развязок и т. д.

При разработке долгосрочной концепции развития транспорта основными принципами ее создания являются: 
- разработанная концепции должна опираться на системный подход, базирующуюся на современном или перспективном развитии науки и техники;

- основной идеей долгосрочной концепции инновационного развития транспорта эта интеллектуальная транспортная система.

Повышения качества и безопасность дорожного движения можно достичь с помощью создания интеллектуальной транспортной системы (ИТС). Интеллектуальная транспортная система эта интеллектуальная система управления, использующая инновационные разработки в моделировании транспортных систем и регулировании транспортных потоков, интегрирующая современные информационные и телематические технологии и предназначенная для автоматизированного поиска и принятия к реализации максимально эффективных сценариев управления транспортно-дорожным комплексом. Внедрения ИТС, как показывает мировая практика, поможет решить вопросы сокращения аварийности, повышения эффективности общественного транспорта и грузоперевозок, обеспечения общей транспортной безопасности, улучшения экологических показателей. ИТС являясь общемировым трендом, позволяет кардинальным образом улучшить качество и безопасность дорожного движения.

С помощью ИТС можно решить следующие актуальные задачи для страны:

- оптимизация распределения транспортных потоков в улично-дорожной сети во времени и пространстве;

- увеличение пропускной способности существующей улично-дорожной сети;

- $\quad$ предоставление приоритетов для проезда определенному типу транспорта;

- повышение безопасности дорожного движения;

- снижение отрицательного экологического воздействия транспорта;

- предоставление информации о дорожной обстановке участникам транспортного процесса и т.д.

В мире существуют различные концепции уже апробированных ИТС. В зависимости от ряда политических и социальных особенностей той или иной страны, приоритеты в предоставляемых сервисах расставляются по-разному. В одних странах государство обеспечивает развитие ИТС и зарабатывает на предоставляемых сервисах, в других - идет по пути развитию коммерческих ИТС с регулированием в основном социальной сферы и систем безопасности. С учетом различных апробированных систем ИТС многие страны с развитой экономикой имеют свои национальные концепции и приоритетные программы развертывания ИТС, что находит отражение в их программных документах.

Опыт стран Евросоюза, США, Японии, Китая и других государств в продвижении проектов ИТС показывает, что в условиях рыночной экономики только единая государственная политика позволяет объединить усилия государства и его субъектов, бизнеса всех уровней и секторов экономики в решении общенациональных целей в транспортном комплексе. Государство осуществляет стратегически-инновационную функцию - поддерживает базисные технологические и экономические инновации, придавая им начальный импульс. При формировании интеллектуальной транспортной системы. Основная роль государства может быть:

- организующая и координирующая - в создании институциональной основы для разработки национальной архитектуры ИТС и координационных планов развития;

- регулирующая - создание правового поля, стандартизация параметров в сфере безопасности и технической совместимости;

- стимулирующая - поддержка исследований и социально-ориентированных проектов ИТС- сервисов в сфере общественного транспорта и неотложных служб;

- инвестиционная - разработка и реализация ИТС-проектов, решающих задачи безопасности и производительности, которые могут создаваться и эксплуатироваться с привлечением частного капитала на условиях государственно-частного партнерства.

В настоящее время государственная политика Грузии в сфере интеллектуальных транспортных систем не выстроена и действующими стратегическими и программными документами не определена и находятся на зачаточном уровне. Тем не менее разрабатываются отдельные элементы, в наиболее обширной сфере применения ИТС - в обеспечение безопасности дорожного движения. Широко применяются дорожные камеры фиксации нарушений правил дорожного движения. Они детектируют различные нарушения правил, от 
превышения скоростного режима, до сложных, комбинированных нарушений на перекрестках, пешеходных переходах, распознают автомобильные номера, создают доказательную базу, передавая ее в центр обработки данных. Применение информационных технологий не обходит стороной и сферу общественного транспорта, где используют видеонаблюдение, детектирующее нарушения общественного порядка. Грузинский технический университет готовит специалистов по курсу «Телематические системы». Предполагается прилагать больше усилий для внедрения интеллектуальной и эффективной транспортной системы за счет современных технологий.

В государственной стратегии развития ИТС должно быть отражено видение данной отрасли в долгосрочной перспективе. Необходимо, чтобы она включала в себя такие цели, как повышение безопасности транспорта, обеспечение предсказуемости транспортных потоков и информированности пользователей, функционирование экологически безопасной транспортной системы, создание комфортных условий проживания в городах. Национальная интеллектуальная транспортная система должна быть унифицирована с международными интеллектуальными транспортными системами, поэтому такую систему целесообразно создавать в сотрудничестве с европейскими странами, учитывая специфические особенности страны. Внедрение ИТС управления дорожным движением позволит снизить аварийные, экономические и экологические, а также социальные потери в сфере дорожного движения несмотря на рост автомобилизации.

Выводы. Долгосрочная концепция развития транспорта Грузии должна опираться на передовые достижения науки и техники. Современные интеллектуальные транспортные систему являются новым типом систем управления, пришедшими на смену автоматизированных и информационным системам управления. Они учитывают такие важные факторы как распределенная информация и пространственные отношения. Интеллектуальные транспортные системы служат инструментом принятия решений в условиях большой сложности и больших объемов данных. При разработке долгосрочной концепции инновационного развития транспорта в Грузии в качестве основной идеи следует использовать интеллектуальные транспортные системы и концепцию долгосрочного инновационного развития транспорта, создавать их на основе современных информационных и телематических технологии.

\section{REFERENCES}

1. Statistical Yearbook of Georgia: 2019 / National Statistics Office of Georgia. - Tbilisi, 2019, 290 p.

2. Anand Paul, Naveen Chilamkurti, Alfred Daniel, Seungmin Rho. Intelligent transportation systems // intelligent Vehicular Networks and Communications, 2017, $41 \mathrm{p}$.

3. Kala Rahul. Basics of intelligent Transportation Systems//On-Road intelligent Vehicles, 2016, 458 p. 